\title{
Metabarcoding dietary analysis of coral dwelling predatory fish demonstrates the minor contribution of coral mutualists to their highly partitioned, generalist diet
}

Matthieu Leray, Christopher P Meyer, Suzanne C Mills

Understanding the role of predators in food webs can be challenging in highly diverse predator/prey systems composed of small cryptic species. DNA based dietary analysis can supplement predator removal experiments and provide high resolution for prey identification. Here we use a metabarcoding approach to provide initial insights into the diet and functional role of coral-dwelling predatory fish feeding on small invertebrates. Fish were collected in Moorea (French Polynesia) where the BIOCODE project has generated DNA barcodes for numerous coral associated invertebrate species. Pyrosequencing data revealed a total of 292 Operational Taxonomic Units (OTU) in the gut contents of the arceye hawkfish (Paracirrhites arcatus), the flame hawkfish (Neocirrhites armatus) and the coral croucher (Caracanthus maculatus). 149 (51\%) of them had species-level matches in reference libraries (>98\% similarity) while 76 additional OTUs (26\%) could be identified to higher taxonomic levels. Decapods that have a mutualistic relationship with Pocillopora and are typically dominant among coral branches, represent a minor contribution of the predators' diets. Instead, predators mainly consumed transient species including pelagic taxa such as copepods, chaetognaths and siphonophores suggesting non random feeding behavior. We also identified prey species known to have direct negative interactions with stony corals, such as Hapalocarcinus sp, a gall crab considered a coral parasite, as well as species of vermetid snails known for their deleterious effects on coral growth. Pocillopora DNA accounted for $20.8 \%$ and $20.1 \%$ of total number of sequences in the guts of the flame hawkfish and coral croucher but it was not detected in the guts of the arc-eye hawkfish. Comparison of diets among the three fishes demonstrates remarkable partitioning with nearly $80 \%$ of prey items were consumed by only one predator. Overall, the taxonomic resolution provided by the metabarcoding approach highlights a highly complex interaction web and demonstrates that levels of trophic partitioning among coral reef fishes have likely been underestimated. Therefore, we strongly encourage further empirical approaches to dietary studies prior to making assumptions of trophic equivalency in food web reconstruction. 
2 Metabarcoding dietary analysis of coral dwelling predatory fish demonstrates the minor

3 contribution of coral mutualists to their highly partitioned, generalist diet.

4

5 Matthieu Leray ${ }^{1,2,3^{*}}$, Christopher P. Meyer ${ }^{3}$, Suzanne C. Mills ${ }^{1,2}$

6

$7{ }^{1}$ USR 3278 CRIOBE CNRS-EPHE-UPVD, CBETM de l'Université de Perpignan, 66860

8 Perpignan Cedex, France

92 Laboratoire d'Excellence "CORAIL"

$10{ }^{3}$ Department of Invertebrate Zoology, National Museum of Natural History, Smithsonian

11 Institution, P.O. Box 37012, MRC-163, Washington, DC 20013, USA

12

13

$14 *$ E-mail: leray.upmc@gmail.com 


\section{Introduction}

Anthropogenic stressors are impacting all ecosystems on Earth, causing both drastic changes in the structure of communities and a reduction in biodiversity (Wright, 2005; Hoegh-Guldberg \& Bruno, 2010). Predators are among the most vulnerable trophic group, and have long been known to play a crucial role in stabilizing ecosystems by generating top-down forces and trophic cascades (Paine, 1966, 1969). Yet because all predator species are not functionally equivalent, understanding how species partition their diet and their ecological role in food webs have become a major focus to help predict the consequences of their decline on ecosystem services (Harley, 2011).

A detailed knowledge of a predator's diet is a key element for deciphering its ecological function. Among the numerous techniques used in the literature to characterize a predator's diet, PCR-based molecular analysis of gut contents is among the most powerful because species-diagnostic DNA fragments can be detected even after several hours of digestion (Symondson, 2002). Moreover, the availability of versatile PCR primers targeting short hypervariable DNA regions combined with a high-throughput sequencing platform now offer the possibility to characterize the dietary breadth of any predator (Pompanon et al., 2012; Leray et al., 2013a). The ecological influence of a predator may then be inferred from its dietary selectivity as well as the traits and functional role of prey consumed (Chapman et al., 2013). On land, this tool is already proving invaluable for understanding the biological control potential of insect predators (Mollot et al., 2014) and the ecological effects of large herbivores (Kowalczyk et al., 2011) and carnivores (Shehzad et al., 2012). On the other hand, the use of high-throughput sequencing for understanding trophic links in marine systems has been more limited to date (Leray et al., 2013a).

On coral reefs, one of the most diverse and threatened ecosystems, predatory fish feeding on benthic invertebrates are the dominant trophic category. They often dwell within the reef framework where they feed upon diverse communities of small cryptic species that are known to perform a variety of functions including direct positive or negative interactions with stony corals, the foundation species of the coral reef ecosystem (reviewed by Stella et al., 2011). Some invertebrate taxa benefit the survival and growth of corals by slowing the progression of coral diseases (Pollock et al., 2012), protecting corals against corallivores (Glynn 1980, 1983; McKeon and Moore 2014; Rouzé et al., 2014), removing sediments from their coral host 
47 (Stewart et al., 2006; Stier et al., 2012) and alleviating detrimental effects of coral competitors or 48 parasites (Stier et al., 2010). Other invertebrates have deleterious effects on corals as they are known vectors of coral diseases (Sussman et al., 2003; Williams \& Miller, 2005), are parasites of stony corals (Humes, 1985; Shima, Osenberg \& Stier, 2010) or feed upon coral polyps (Turner, 1994; Rotjan \& Lewis, 2008; Rawlinson et al., 2011) sometimes causing extensive and widespread coral mortality (Leray et al., 2012a; Kayal et al., 2012). As a consequence, the feeding behavior of these predatory fish may have significant cascading effects on the dynamics of stony corals and subsequently the dynamics of the whole coral reef ecosystem, but it has proven challenging to understand their ecological role.

The flame hawkfish (Neocirrhites armatus), arc-eye hawkfish (Paracirrhites arcatus) and coral croucher (Caracanthus maculatus) are common predatory fish species on Indo-Pacific coral reefs. They co-occur among the branches of Pocilloporids (genus Stylophora and Pocillopora), one of the most important reef building corals, along with a wide diversity of invertebrates (Patton, 1974; Coles, 1980; Odinetz, 1983; Stella, Jones \& Pratchett, 2010). These invertebrates include both coral mutualistic (family: Trapeziidae and some Alpheidae) and parasitic (family: Cryptochiridae) decapod species (Simon-Blecher \& Achituv, 1997), which are potential prey for coral dwelling fish. A field manipulation of the two Pocilloporid obligate species, the flame hawkfish and the coral croucher (habitat specialists), highlighted that their presence among the branches of Pocillopora eydouxi reduced total abundance and diversity of decapod recruits by $34 \%$ and $20 \%$ respectively (Stier \& Leray, 2014). These predators modified the composition and abundance of key mutualists (coral crabs, genus: Trapezia), whose benefits to Pocillopora are known to be both density- and diversity- dependent (Stier et al., 2012). Predator removal experiments have also shown that the presence of arc-eye hawkfish decreases the density of coral associated mutualist damselfish (Holbrook, Schmitt \& Brooks, 2011). Preliminary molecular dietary analysis using traditional cloning showed the presence of coral mutualists in the gut contents of both hawkfish species (Leray et al., 2013b), but sampling and sequencing effort were too limited to understand their contribution to each species' diets.

In the present study, we use a high throughput sequencing approach targeting the mitochondrial Cytochrome c. Oxidase subunit I gene (COI) (also referred to as metabarcoding approach, Taberlet et al., 2012) to describe the dietary breadth of these predators. The study was conducted in Moorea, French Polynesia, where an extensive library of COI DNA barcodes, 
78 including all Pocillopora associated species, has been built by the BIOCODE project (Leray et 79 al., 2012b). Implications of each predator's feeding behavior are further discussed in light of our 80 findings.

81

\section{Methods}

Predator and prey collections

84 Twenty-five adult specimens of each of the three predator fish species were speared after sunset, 85 which corresponds to peak feeding time for all three species (M Leray, personal observation), in 86 the lagoon of the North shore of Moorea on the $8^{\text {th }}, 10^{\text {th }}$ and $15^{\text {th }}$ of July 2010 . We limited our 87 collections to a single site $\left(17^{\circ} 28^{\prime} 40 \mathrm{~S} ; 149^{\circ} 50^{\prime} 25 \mathrm{~W}\right.$, Fig. 1$)$ where coral populations have been 88 little impacted by the recent outbreak of the corallivorous seastar, Acanthaster planci (Adjeroud 89 et al., 2009; Kayal et al., 2011; Rouzé et al., 2015). Adults of the flame hawkfish and coral croucher always co-occurred among Pocillopora branches, whereas adult arc-eye hawkfish were occasionally present. Fish were individually preserved in cold 50\% ethanol in situ after which their digestive track was dissected within 3 hours and preserved in eppendorf tubes containing $80 \%$ ethanol. Approval was granted from our institutional animal ethics committee, le Centre National de la Recherche Scientifique (CNRS), for sacrificing and subsequently dissecting fish (Permit Number: 006725). None of the fish species are on the endangered species list and no specific authorization was required from the French Polynesian government for collection.

\section{Laboratory protocol}

The total content of the digestive track of each fish was dissected and used for total genomic DNA extraction using the QIAGEN DNeasy Blood \& Tissue kit. Genomic DNA was then purified using the PowerClean DNA clean-up kit (MO BIO) to remove potential PCR inhibitors. We used a single set of versatile PCR primers (mlCOIintF/jgHCO2198, Geller et al., 2013; Leray et al., 2013a) known to perform well across the diversity of marine invertebrates, to amplify a 313bp region of the mitochondrial Cytochrome c. Oxidase subunit I (COI) region from each gut content sample. Moreover, this primer set was recently shown to provide reliable estimates of relative abundance for metabarcoding benthic samples (Leray \& Knowlton, 2015). Because predator DNA co-amplification is known to impede prey detection (Vestheim \& Jarman, 2008), predator-specific annealing blocking primers were included at ten times the 
109

110

111

112

113

114

115

116

117

118

119

120

121

122

123

124

125

126

127

128

129

130

131

132

133

134

135

136

137

138

concentration of versatile primers during PCR reactions as in Leray et al. (2013a). All primer sequences are provided in Table 1. The PCR cocktail and touchdown temperature profile used in this study can both be found in Leray et al. (2013a). Three PCR replications per sample were generated, pooled, gel excised to ensure that all primer dimers were screened away, purified using QIAGEN® MinElute columns and eluted in $12 \mu$ of elution buffer. PCR product concentration was measured with the Qubit ${ }^{\circledR}$ Fluorometer (Invitrogen).

We pooled equimolar amounts of the combined amplicons per individual gut content for each predator species (e.g. 25 flame hawkfish gut content samples were pooled together) and 500 ng of PCR product was used per species for library preparation for Roche 454 FLX sequencing. Amplicons were end-repaired and dA-tailed using the NEBNext Quick DNA Sample Prep Reagent Set 2 chemistry (New England BioLabs). We then performed a ligation of 454 Multiplex Identifiers (a total of three, each one containing a recognizable sequence tag) using the FLX Titanium Rapid Library MID Adaptors Kit (Roche). Finally, the ligated PCR product of each sample was purified using Agencourt AMPure beads (Beckman Coulter Genomics), eluted in $40 \mu 1$ of TE buffer, and the three samples pooled together for sequencing at the Duke Institute for Genome Sciences and Policy (Duke University, NC, USA). Note that the three samples of the present study were combined with several other samples in the same 454 run.

\section{Analysis of FLX sequencing data}

We followed a sequence data analysis pipeline optimized for analyzing large COI datasets. The pipeline detailed in Leray et al. (2013a) takes advantage of the coding properties of the barcoding region to discard all dubious sequences.

An initial step denoised flowgrams using Pyronoise (Quince et al., 2011) implemented in Mothur (Schloss et al., 2009). We then further quality filtered the dataset by removing any reads with the following criteria: shorter than 200bp; more than two mismatches in the primers sequence; any ambiguous base calls (e.g. "N"); or with any homopolymer regions longer than $8 \mathrm{bp}$. Remaining sequences were subsequently aligned to a high quality reference dataset (Moorea BIOCODE barcode library) based on amino acid translations using the option “enrichAlignment" in MACSE (Ranwez et al., 2011) and all sequences with any of the following were also discarded: stop codon; frame shift; insertion; or more than three deletions. Finally, 
139 potential chimeric sequences identified using UCHIME (Edgar et al., 2011) were removed to 140 obtain a high quality sequence dataset for downstream analysis.

141 To evaluate prey richness and composition, sequences were clustered in Operational 142 Taxonomic Units (OTUs) using a Bayesian algorithm implemented in CROP (Hao, Jiang \& 143 Chen, 2011). This program delineates OTUs based on the natural distribution of sequence 144 dissimilarity in the data and within a range of sequence similarity values defined by the user.

145 This approach performs better for clustering sequences obtained from environmental samples 146 than a fixed dissimilarity cutoff (e.g. 5\%) because they contain a diversity of phyla that differ in 147 their rate of COI evolution. The lower and upper bound variance were set to 3 and 4 respectively 148 (which corresponds to $6 \%$ and $8 \%$ ) as they were shown to provide the best results for marine 149 invertebrates (Leray et al., 2013a,b). Following OTU delineation, a representative sequence per 150 OTU was used for taxonomic identification using BLAST searches in the local BIOCODE

151 database and in GENBANK. We considered that there was a species level match when sequence 152 similarity was at least 98\% (Machida et al., 2009; Plaisance et al., 2009). Whenever sequence 153 similarity was lower than $98 \%$, we used a Bayesian approach implemented in the Statistical 154 Assignment Package (SAP, Munch et al., 2008) to assign OTUs to a higher taxonomic group. 155 SAP conducts assignments by building 10,000 unrooted phylogenetic trees from a collection of 156 homologue sequences retrieved from a sequence database. It then calculates the probability that a 157 query sequence belongs to a monophyletic group within that set of homologues. Here, we 158 allowed SAP to retrieve 50 homologues from GENBANK with $>70 \%$ sequence similarity to 159 each query sequence (i.e. each OTU representative sequence) and accepted taxonomic assignments at an $80 \%$ posterior probability cutoff. Importantly, SAP can only assign sequences to taxonomic groups that are represented in the database, as is also the case with other assignment methods. Therefore, to minimize misidentification at lower taxonomic levels, we only report assignments to the phylum, class and order levels (Appendix 1).

\section{Results}

166 We obtained 69,663 reads of which 54,283 high quality reads were retained after alignment 167 based on amino acid translation (arc-eye hawkfish: 24,629; flame hawkfish: 13,536; coral 168 croucher: 16,118). The Bayesian clustering algorithm delineated 292 OTUs in the gut contents of 169 the three predatory fish species (Appendix 1). The number of dietary items was much lower in 
170 the gut contents of the coral croucher (64 taxa) than in both arc-eye (147 taxa) and flame

171 hawkfish (149 taxa). BLAST searches provided high-resolution taxonomic assignments ( $>98 \%$

172 similarity) for 149 OTUs (51\%) (Appendix 1) and the statistical assignment approach enabled

173 the identification of 76 additional OTUs to a higher taxonomic level (26\%). 67 OTUs (22.9\%)

174 remained unidentified (labeled as "Unidentified" in Appendix I). None of the rarefaction curves

175 reached a plateau (Fig. 2) which indicates that further sequencing effort would be necessary for a

176 more exhaustive dietary analysis of these predatory fish.

177 The diversity of dietary items spanned 25 classes belonging to 17 phyla. Malacostraca

178 was the dominant taxonomic prey group $(36.7 \%, 21.5 \%$ and $43.7 \%$ for the arc-eye hawkfish, the

179 flame hawkfish and the coral croucher, respectively). The arc-eye hawkfish also consumed 180 numerous species of Actinopterygii (17.7\% total OTUs) and Maxillopoda (10.9\% total OTUs). A 181 significant proportion of the flame hawkfish and coral croucher's diet was represented by 182 Maxillopoda (12.1\% and 6.2\% total OTUs, respectively) and Gastropoda (9.4\% and 4.7\% total 183 OTUs, respectively). Eighteen OTUs (28\%) detected in the gut contents of the coral croucher 184 remained unidentified. Direct matches to reference barcodes ( $>98 \%$ similarity) were more 185 prevalent among Actinopterygii (94.1\%), Malacostraca (74.1\%) and Gastropoda (79.2\%) 186 compared to Maxillopoda (40\%). Moreover, direct matches were more prevalent for OTUs 187 represented by large numbers of sequences (Fig. 3). Almost nine of ten OTUs (86.7\%) matched 188 reference barcodes if they were common in the amplicon libraries ( $>1000$ sequences), whereas 189 only a third $(33.8 \%)$ of the single sequences matched a reference sequence. Probability of a 190 match increased as the number of sequences increased (1: 33.8\%; [2-9]: 43.7\%; [10-99]: 52.2\%; 191 [100-999]: 70\%; >1000: 86.7\%; Fig. 3).

192 Most Malacostraca OTUs were decapods $(81.5 \%, 46.9 \%$ and $78.6 \%$ for the arc-eye 193 hawkfish, the flame hawkfish and the coral croucher respectively - Appendix 1). All three 194 predatory fish fed upon Pocillopora obligate decapod species, but they represent a minor fraction 195 of the total diversity of the prey they consumed (arc-eye hawkfish: $2 \%$; flame hawkfish: $4 \%$, 196 coral croucher: 9.3\%). Among them, we detected five coral crab species of the genus Trapezia 197 that are mutualists of Pocillopora (Trapezia bidentata, T. serenei, T. rufopunctata, T. areolata 198 and $T$. spp). These mutualists also represented a minor proportion of sequences in the gut 199 contents of the arc-eye and flame hawkfish (proportion of total sequences: $5.6 \%$ and $2.4 \%$; 200 proportion of decapod sequences: $9.1 \%$ and $12.7 \%$, respectively). Pocillopora mutualists 
201 represented a higher proportion of the coral croucher's diet with $15.3 \%$ of the total number of 202 sequences and $47.9 \%$ of the total number of decapod sequences.

203 Additional trophic links involving non-decapod prey are of particular interest for 204 understanding the effect of predators on coral and its associated communities. Predatory fish had 205 fed upon coral associated planktivorous damselfishes of the family Pomacentridae (Dascyllus 206 flavicaudus: $0.02 \%, 0 \%$ and $0.12 \%$, Chromis viridis: $0.01 \%, 0.69 \%$ and $0 \%$ of total sequences in 207 the diet of the arc-eye hawkfish, the flame hawkfish and the coral croucher, respectively) that 208 benefit the growth of the coral host (Holbrook et al., 2008). Interestingly, Anthozoa were 209 represented by two OTUs among which the host Pocillopora itself accounted for $20.8 \%$ and $21020.1 \%$ of total number of sequences in the guts of flame hawkfish and coral croucher, but was 211 completely absent from the gut of the arc-eye hawkfish. On the other hand, Hapalocarcinus sp, a 212 gall crab considered a coral parasite, was recovered in the diet of both the arc-eye and flame 213 hawkfish. Both hawkfish had also consumed vermetid snails known for their deleterious effects 214 on coral growth (Shima, Osenberg \& Stier, 2010). Harpiliopsis beaupresii, a caridean shrimp 215 associated with Pocillopora but whose function is unknown, was also detected in the gut 216 contents of the coral croucher. Almost 10 percent (8.3\%) of the coral croucher's diet is 217 composed of two snails (Drupa ricinus and Pascula muricata). Finally, predators had also 218 consumed pelagic taxa including members of Maxillipoda, Chaetognatha and Hydrozoa 219 (Appendix 1).

220 Prey species were remarkably partitioned among predators (Fig. 4). Almost eighty 221 percent (79.5\%) of prey species had been consumed by only one predator species (232 of 292). 222 Eighteen percent $(\mathrm{N}=52)$ were found in two predator diets and only eight prey species $(>3 \%)$ had 223 been ingested by all three predatory fish species analyzed. Of the shared components, the arc-eye 224 hawkfish and the coral croucher had consumed 14 taxa in common among which six were 225 Malacostraca. The arc-eye and flame hawkfish shared 29 prey taxa with a majority of 226 Actinopterygii and Malacostraca. Prey sharing was lowest (nine OTUs; of which six were 227 Malacostraca) between the two species that were always found co-occuring together in the coral 228 host, the flame hawkfish and coral croucher. Analyses that included only prey OTUs consisting 229 of $>1 \%$ of either of the three species diets according to the relative abundance of reads 230 demonstrate even greater partitioning (Fig. 4). Only six of the sixty-six prey items were shared at 231 a proportion greater than $1 \%$ in any two fish species diets, and no prey species were shared 
232 among all three. Of the 66 prey items making up at least $1 \%$ of any diet, nine out of ten were 233 consumed by only one predator. An alignment of all OTU representative sequences is provided

234 in Appendix 2 and the raw sequence dataset was deposited in the Dryad Repository

235 doi:XXXXXXXXXXXXXX).

236

\section{Discussion}

238 Dietary analysis can be a powerful approach to gain insights into the ecological role of reef239 dwelling predatory fish, but low taxonomic resolution in prey identification often obscures the 240 complexity of trophic links (Longenecker, 2007). For example, the diet of the arc-eye hawkfish, 241 flame hawkfish and coral croucher previously described from morphological identification of 242 prey remains in gut contents was considered to be simply composed of small benthic crustaceans 243 (class: Malacostraca) (Bachet, Zysman \& Lefevre, 2007). Preliminary DNA analysis using 244 traditional cloning revealed a breadth of prey species in the guts of the arc-eye and flame 245 hawkfish, the majority of which were crustaceans 18 of 24 (75\%) and 21 of 31 (68\%) 246 respectively (Leray et al., 2013b). This study highlights that a metabarcoding approach 247 significantly increases the taxonomic scope by documenting an even broader taxonomic 248 distribution of species consumed by hawkfishes (Appendix 1). The coral croucher diet also 249 includes a wide spectrum of prey demonstrating that all three predatory fish feed broadly across 250 community diversity. Our results highlight the importance of collecting empirical dietary data to 251 understand processes of species coexistence in this high diversity marine ecosystem.

252 The ecological influence of a predator is contingent upon the prey it consumes. Their 253 feeding behavior may induce cascading effects that will depend on the type of association that 254 the prey they consume (or interfere with) have with keystone species. For example, in terrestrial 255 ecosystems where up to $90 \%$ of flowering plant species use animal pollinators for reproduction 256 (Bushmann \& Nabhan, 1996), a predator's effect on plant reproductive success, growth and 257 survival will depend on its relative consumption of pollinators and phytophageous insects 258 (Dukas, 2005; Knight et al., 2006). Similarly, some coral reef dwelling predatory fish may either 259 disrupt benefits to corals if they derive a significant proportion of their diet from coral mutualists 260 or alternatively alleviate deleterious effects on corals if they consume coral parasites.

261 Invertebrate communities occurring among the branches of live Pocillopora corals in Moorea or 262 elsewhere in the Pacific are typically composed of a preponderance of decapod mutualists $(>80 \%$ 
263 of diversity and abundance in live Pocillopora- see Patton 1974, Coles 1980, Odinetz 1983,

264 Stella et al., 2010, Leray et al., 2012a). Based on previous cloning studies (Leray et al., 2013b)

265 only the arc-eye hawkfish consumed functionally important prey (Trapezia tigrina). With

266 increased sequencing depth herein, we demonstrate that while many other mutualist decapod

267 species do occur in the diets (Fig. 1, Appendix 1), they represent a much smaller proportion of

268 the diet of the arc-eye hawkfish, flame hawkfish and coral croucher than exist in the natural

269 communities $(5.6 \%, 2.4 \%$ and $15.3 \%$ of sequence abundance, respectively). Interestingly, we

270 found evidence of the Pocillopora obligate pontoniid shrimp Harpiliopsis beaupressi but no

271 detection of congeneric Harpiliopsis depressa and H. spinigera in the predators' gut contents,

272 despite their very high abundance reported on head-size Pocillopora in Moorea (Leray et al.,

273 2012a). It is also surprising not to discover Alpheus lottini in the diets of the three species

274 although this is a common species found in all living Pocillopora observed and known to have

275 beneficial effects on coral survivorship (Stier et al., 2012). Overall, our data indicate a non

276 random pattern of prey consumption atypical of an opportunistic feeding behavior (where prey

277 would be consumed in proportion to their abundance - Heinlein et al., 2010) which suggests the

278 outcome of coevolutionary dynamics between Pocillopora associated predator and prey.

279 Nevertheless, while our metabarcoding dietary analysis suggests limited predation

280 pressure on mutualists, a four-month recruitment experiment conducted on the North shore of

281 Moorea in 2009 showed a lower abundance of mutualists in corals where the coral croucher and

282 the flame hawkfish occurred (Stier \& Leray, 2014), a pattern that may be driven by non-

283 consumptive effects of predators. For example, competent larvae may preferentially settle on

284 corals where predators are absent. Regardless of the mechanisms, such predator effects have

285 important implications for coral performance, because density and composition of mutualist

286 assemblages are known to be important for the quality of the services provided to their host

287 (Stier et al., 2012; Rouzé et al., 2014).

288 In addition, our metabarcoding analyses of gut contents revealed for the first time

289 predation on a gall crab (Hapalocarcinus $s p$ ) and vermetid snails (genus: Dendropoma), which

290 are considered detrimental to the coral host (Simon-Blecher \& Achituv, 1997; Shima, Osenberg

$291 \&$ Stier, 2010). Vermetid snails are particularly prevalent in Moorea where they can reduce coral

292 growth by up to $81 \%$ and survival by up to $52 \%$ (Shima, Osenberg \& Stier, 2010). Predation on

293 parasites may compensate for the negative effects of the reduction in density of decapod 
294 mutualists in corals facing environmental stressors. We also recovered a significant proportion of 295 sequences belonging to Pocillopora from the flame hawkfish and the coral croucher gut contents, 296 which suggest that these predatory fish also feed on mucus released by their biogenic habitat.

297 The absence of Symbiodinium COI sequences from our dataset also supports the consumption of 298 mucus rather than coral polyps. Alternatively, Pocillopora DNA may have been sufficiently 299 abundant and well preserved in the gut contents of mucus feeding prey (e.g. Trapeziidae) to be 300 co-amplified (Harwood et al., 2001; Sheppard et al., 2005). Importantly though, Pocillopora was 301 completely absent from the arc-eye hawkfish diet which also includes Trapeziid species, 302 suggesting minimal secondary consumption or associated eDNA amplification. Overall, high303 resolution dietary data are revealing a highly complex interaction web with very specialized

304 functional roles played by each species. This highlights the shortcomings of the functional 305 groups approach commonly used to evaluate redundancy and complementarity among coral reef 306 species (Naeem \& Wright, 2003; Micheli \& Halpern, 2005).

$307 \quad$ Fine-scale spatial partitioning commonly occurs among coral reef fish species

308 (Robertson \& Lassig, 1980; Waldner \& Robertson, 1980; Ebersole, 1985; Bouchonnavaro, 1986;

309 Munday, Jones \& Caley, 1997; Depczynski \& Bellwood, 2004; Gardiner \& Jones, 2005) but the

310 extent of food partitioning remains controversial (Longenecker, 2007). In fact, most early work

311 investigating differences in diet among reef fish species showed high levels of diet overlap (Hiatt

312 \& Strasburg, 1960; Randall, 1967; Hobson, 1974; Talbot, Russell \& Anderson, 1978; Harmelin-

313 Vivien, 1979; Anderson et al., 1981; Bouchonnavaro, 1986; Ross, 1986; Depczynski \&

314 Bellwood, 2003; Kulbicki et al., 2005; Longenecker, 2007; Castellanos-Galindo \& Giraldo,

315 2008) which has led many to the conclusion that trophic partitioning was not a mechanism

316 promoting species coexistence on coral reefs. However, these studies, which rely on

317 morphological identification of semi-digested prey remains in gut contents grouped food items

318 into broad categories therefore impeding accurate measures of partitioning (Longenecker, 2007).

319 Alternative strategies such as field observations of feeding behavior (Pratchett, 2005, 2007;

320 Pratchett \& Berumen, 2008) or a combination of gut content and stable isotope analyses (Ho et

321 al., 2007; Nagelkerken et al., 2009) helped describe dietary differences between closely related

322 species, but generalizations about the importance of trophic partitioning for the maintenance of

323 coral reef diversity remain difficult. In the present study, high-resolution molecular data

324 highlight an unexpected level of dietary partitioning among the three study species. While both 
325 hawkfish species are from the same family (Cirrhitidae), they share only a single prey item at 326 greater than $1 \%$ of either of their diets (Trapezia serenei). There is also a minor dietary overlap

327 between the coral croucher (family Caracanthidae) and the flame hawkfish that were always

328 found co-occurring in Pocillopora and are known to rarely venture outside the branching

329 structure provided by their host coral (Hiatt \& Strasburg, 1960; Stier \& Leray, 2014). These

330 results demonstrate that levels of trophic partitioning have likely been underestimated. We

331 strongly encourage further empirical approaches to dietary studies prior to making assumptions

332 of trophic equivalency in food web reconstruction (Leibold \& McPeek, 2006).

333 The extent to which secondary prey co-amplification could lead to errors in food web

334 analysis has not been quantified in marine systems (see Sheppard et al., 2005 for an example in

335 terrestrial system). In the present dataset, numerous prey species identified in fish gut contents

336 are either grazers or detritivores (e.g. isopods, amphipods, decapods, ophiuroids and gastropods)

337 and are therefore unlikely to consume each other. Some fish species detected in the gut contents

338 are higher-level predators (e.g. Caranx melampygus) that could consume benthic grazers and

339 detritivores as adults, but they were most likely fed upon at a younger developmental stage (egg,

340 larva or juvenile) given the size of predators. Demospongiae, Ascidiacea and Gymnolaemata

341 represented by few or a single sequence in the dataset were, however, possibly ingested

342 unintentionally as secondary prey or epiphytes on the carapace of spider crabs (e.g. Menaethius

343 monoceros and Perinia tumida). Parasites of prey (e.g. parasitic isopods of coral crabs of the

344 genus Trapezia, Appendix 1) and parasites of a predator's digestive track (e.g. Trematoda and

345 Cestoda) may also confound food web reconstructions and care should be taken to consider the

346 targeted roles these fish predators have on various parasites. The recovery of secondary prey may

347 artificially inflate dietary partitioning if those lower levels are also partitioned. However, we

348 expect the amount of DNA that these secondary prey items represent in the guts of our target

349 predators should be minor and highly digested in comparison to primary prey. A recent

350 metabarcoding analysis of benthic samples (Leray \& Knowlton, 2015) showed evidence of a

351 correlation between amount of DNA and number of reads. Thus if secondary prey is quickly

352 degraded, those taxa should be represented by one or few reads only. The present dataset shows

353 minor dietary overlap both with and without rare OTUs ( $<1 \%$ of total OTUs, fig. 4 ), further

354 supporting our conclusions regarding the extent of trophic partitioning among all three fish

355 species. 
Importantly, our analysis shows that in-depth sequencing would enable a more

357

358

359

360

361

362

363

364

365

366

367

368

369

370

371

\section{Acknowledgements}

376 logistical support. comprehensive representation of trophic links in this multi-faceted ecosystem. Additional reads would provide more OTUs matching reference barcodes (in GENBANK, BOLD or BIOCODE) but also a higher proportion of unidentified OTUs represented by a single sequence ("singleton", Fig. 3) that are likely to be either (1) small taxa underrepresented in DNA barcode libraries (Leray et al., 2013a), or (2) the product of sequencing artifacts despite our very stringent quality filtering based on amino-acid translation. Further barcoding initiatives aiming to catalogue small life forms (e.g. meiofauna) will be crucial to advance our understanding of food webs.

Systematic removal of singletons may also be used as a conservative measure, although most of them likely represent valid taxa (Huse et al., 2010). As coral reef ecosystems decline worldwide, understanding the role of predator species in a dominant, yet largely understudied trophic category, is essential. Our study highlights the tremendous potential of metabarcoding as an approach to provide unprecedented taxonomic resolution in the diet of coral dwelling predatory fish. We encourage that further work should be conducted to understand the ecological role of reef dwelling fish and invertebrates.
373 We thank Gustav Paulay, Arthur Anker, Joseph Poupin and the BIOCODE teams who collected
374 both marine and terrestrial specimens, the "Centre de Recherche Insulaire et Observatoire de
375 l'Environnement (CRIOBE) de Moorea" and the Richard B. Gump field station in Moorea for
374 both marine and terrestrial specimens, the "Centre de Recherche Insulaire et Observatoire de
375 l'Environnement (CRIOBE) de Moorea" and the Richard B. Gump field station in Moorea for

377 
382

383

384

385

386

387

388

389

390

391

392

393

\section{References}

Adjeroud M, Michonneau F, Edmunds PJ, Chancerelle Y, de Loma TL, Penin L, Thibaut L, Vidal-Dupiol J, Salvat B, Galzin R. 2009. Recurrent disturbances, recovery trajectories, and resilience of coral assemblages on a South Central Pacific reef. Coral Reefs 28:775-780.

Anderson GR V, Ehrlich AH, Ehrlich PR, Roughgarden JD, Russell BC, Talbot FH. 1981. The community structure of coral reef fishes. American Naturalist 117:476-495.

Bachet P, Zysman T, Lefevre Y. 2007. Guide des poissons de Tahiti et de ses iles.

Bouchonnavaro Y. 1986. Partitioning of food and space resources by chaetodontid fish on coral reefs. Journal of Experimental Marine Biology and Ecology 103:21-40.

Bushmann S, Nabhan G. 1996. The Forgotten Pollinators. Washington, DC: Island Press.

Castellanos-Galindo GA, Giraldo A. 2008. Food resource use in a tropical eastern Pacific tidepool fish assemblage. Marine Biology 153:1023-1035.

Chapman EG, Schmidt JM, Welch KD, Harwood JD. 2013. Molecular evidence for dietary selectivity and pest suppression potential in an epigeal spider community in winter wheat. Biological Control 65:72-86.

Coles SL. 1980. Species diversity of decapods associated with living and dead reef coral Pocillopora meandrina. Marine Ecology-Progress Series 2:281-291.

Depczynski M, Bellwood DR. 2003. The role of cryptobenthic reef fishes in coral reef trophodynamics. Marine Ecology-Progress Series 256:183-191.

Depczynski M, Bellwood DR. 2004. Microhabitat utilisation patterns in cryptobenthic coral reef fish communities. Marine Biology 145:455-463.

Dukas R. 2005. Bumble bee predators reduce pollinator density and plant fitness. Ecology 86:1401-1406.

Ebersole JP. 1985. Niche separation of two damselfish species by aggregation and differential microhabitat utilization. Ecology 66:14-20.

Edgar RC, Haas BJ, Clemente JC, Quince C, Knight R. 2011. UCHIME improves sensitivity and speed of chimera detection. Bioinformatics 27:2194-2200.

Gardiner N, Jones G. 2005. Habitat specialisation and overlap in a guild of coral reef cardinalfishes (Apogonidae). Marine Ecology Progress Series 305:163-175. 
407

Geller JB, Meyer CP, Parker M, Hawk H. 2013. Redesign of PCR primers for mitochondrial Cytochrome c. oxidase subunit I for marine invertebrates and application in all-taxa biotic surveys. Molecular Ecology Resources 13:851-861.

Glynn PW. 1980. Defense by symbiotic crustacea of host corals elicited by chemical cues from predator. Oecologia 47:287-290.

Glynn PW. 1983. Increased survivorship in corals harboring crustacean symbionts. Marine Biology Letters 4:105-111.

Hao X, Jiang R, Chen T. 2011. Clustering 16S rRNA for OTU prediction: a method of unsupervised Bayesian clustering. Bioinformatics 27:611-618.

Harley CDG. 2011. Climate change, keystone predation, and biodiversity loss. Science 334:1124-1127.

Harmelin-Vivien ML. 1979. Ichthyofaune des recifs coralliens de Tulear (Madagascar): ecologie et relations trophiques. Aix-Marseilles, France: University of Aix-Marseilles.

Harwood JD, Phillips SW, Sunderland KD, Symondson WOC. 2001. Secondary predation: quantification of food chain errors in an aphid-spider-carabid system using monoclonal antibodies. Molecular Ecology 10:2049-2057.

Heinlein JM, Stier AC, Steele MA. 2010. Predators reduce abundance and species richness of coral reef fish recruits via non-selective predation. Coral Reefs 29:527-532.

Hiatt RW, Strasburg DW. 1960. Ecological relationships of the fish fauna on coral reefs on the Marshall Islands. Ecological Monographs 30:66-127.

Ho CT, Kao SJ, Dai CF, Hsieh HL, Shiah FK, Jan RQ. 2007. Dietary separation between two blennies and the Pacific gregory in northern Taiwan: evidence from stomach content and stable isotope analyses. Marine Biology 151:729-736.

Hobson ES. 1974. Feeding relationships of teleostean fishes on coral reefs in Kona, Hawaii. Fishery Bulletin 72:915-1031.

Hoegh-Guldberg O, Bruno JF. 2010. The impact of climate change on the world's marine ecosystems. Science 328:1523-8.

Holbrook SJ, Brooks AJ, Schmitt RJ, Stewart HL. 2008. Effects of sheltering fish on growth of their host corals. Marine Biology 155:521-530.

Holbrook SJ, Schmitt RJ, Brooks AJ. 2011. Indirect effects of species interactions on habitat provisioning. Oecologia 166:739-749. 
Humes A. 1985. A review of the Xarifiidae (Copepoda, Poecilostomatoida), parasites of scleractinian corals in the Indo-Pacific. Bulletin of Marine Science 36:467-632.

Huse SM, Welch DM, Morrison HG, Sogin ML. 2010. Ironing out the wrinkles in the rare biosphere through improved OTU clustering. Environmental Microbiology 12:1889-1898.

Kayal M, Lenihan HS, Pau C, Penin L, Adjeroud M. 2011. Associational refuges among corals mediate impacts of a crown-of-thorns starfish Acanthaster planci outbreak. Coral Reefs 30:827-837.

Kayal M, Vercelloni J, Lison de Loma T, Bosserelle P, Chancerelle Y, Geoffroy S, Stievenart C, Michonneau F, Penin L, Planes S, Adjeroud M. 2012. Predator crown-of-thorns starfish (Acanthaster planci) outbreak, mass mortality of corals, and cascading effects on reef fish and benthic communities. PloS One 7:e47363.

Knight TM, Chase JM, Hillebrand H, Holt RD. 2006. Predation on mutualists can reduce the strength of trophic cascades. Ecology Letters 9:1173-1178.

Kowalczyk R, Taberlet P, Coissac E, Valentini A, Miquel C, Kamiński T, Wójcik JM. 2011. Influence of management practices on large herbivore diet - Case of European bison in Białowieża Primeval Forest (Poland). Forest Ecology and Management 261:821-828.

Kulbicki M, Bozec Y-M, Labrosse P, Letourneur Y, Mou-Tham G, Wantiez L. 2005. Diet composition of carnivorous fishes from coral reef lagoons of New Caledonia. Aquatic Living Resources 18:231-250.

Leibold MA, McPeek MA. 2006. Coexistence of the niche and neutral perspectives in community ecology. Ecology 87:1399-1410.

Leray M, Beraud M, Anker A, Chancerelle Y, Mills S. 2012a. Acanthaster planci outbreak: decline in coral health, coral size structure modification and consequences for obligate decapod assemblages. Plos One 7:e35456.

Leray M, Boehm JT, Mills SC, Meyer CP. 2012b. Moorea BIOCODE barcode library as a tool for understanding predator-prey interactions: insights into the diet of common predatory coral reef fishes. Coral Reefs 31:383-388.

Leray M, Yang JY, Meyer CP, Mills SC, Agudelo N, Ranwez V, Boehm JT, Machida RJ. 2013a. A new versatile primer set targeting a short fragment of the mitochondrial COI region for metabarcoding metazoan diversity: application for characterizing coral reef fish gut contents. Frontiers in Zoology 10:34.

Leray M, Agudelo N, Mills SC, Meyer CP. 2013b. Effectiveness of annealing blocking primers versus restriction enzymes for characterization of generalist diets: unexpected prey revealed in the gut contents of two coral reef fish species. Plos One 8:e58076. 
472

473

474

475

476

477

478

479

480

481

482

483

484

485

486

487

488

489

490

491

492

493

494

495

496

497

498

499

500

501

502

503

504

Leray M, Knowlton N. 2015. DNA barcoding and metabarcoding of standardized samples reveal patterns of marine benthic diversity. Proceedings of the National Academy of Sciences of the United States of America 112:2076-2081.

Longenecker K. 2007. Devil in the details: High-resolution dietary analysis contradicts a basic assumption of reef-fish diversity models. Copeia 3:543-555.

Machida RJ, Hashiguchi Y, Nishida M, Nishida S. 2009. Zooplankton diversity analysis through single-gene sequencing of a community sample. BMC Genomics 10:438.

Micheli F, Halpern BS. 2005. Low functional redundancy in coastal marine assemblages. Ecology Letters 8:391-400.

Mollot G, Duyck P-F, Lefeuvre P, Lescourret F, Martin J-F, Piry S, Canard E, Tixier P. 2014. Cover cropping alters the diet of arthropods in a banana plantation: a metabarcoding approach. PloS One 9:e93740.

Munch K, Boomsma W, Huelsenbeck JP, Willerslev E, Nielsen R. 2008. Statistical assignment of DNA sequences using Bayesian phylogenetics. Systematic Biology 57:750-757.

Munday PL, Jones GP, Caley MJ. 1997. Habitat specialisation and the distribution and abundance of coral-dwelling gobies. Marine Ecology-Progress Series 152:227-239.

Naeem S, Wright JP. 2003. Disentangling biodiversity effects on ecosystem functioning: deriving solutions to a seemingly insurmountable problem. Ecology Letters 6:567-579.

Nagelkerken I, van der Velde G, Wartenbergh SLJ, Nugues MM, Pratchett MS. 2009. Cryptic dietary components reduce dietary overlap among sympatric butterflyfishes (Chaetodontidae). Journal of Fish Biology 75:1123-1143.

Odinetz MO. 1983. Ecologie et structure des peuplements de crustaces decapodes associes aux coraux du genre Pocillopora en Polynesie Francaise et en Micronesie (Guam). Paris: Universite Pierre et Marie Curie.

Paine RT. 1966. Food web complexity and species diversity. American Naturalist 100:65-75.

Paine RT. 1969. A note on trophic complexity and community stability. American Naturalist 103:91-93.

Patton WK. 1974. Community structure among the animals inhabiting the coral Pocillopora damicornis at Heron Island, Australia. In: Vernberg WB ed. Symbiosis in the sea. Columbia: University of South Carolina Press.

Plaisance L, Knowlton N, Paulay G, Meyer C. 2009. Reef-associated crustacean fauna: biodiversity estimates using semi-quantitative sampling and DNA barcoding. Coral Reefs 28:977-986. 
505

506

507

508

Pollock FJ, Katz SM, Bourne DG, Willis BL. 2012. Cymo melanodactylus crabs slow progression of white syndrome lesions on corals. Coral Reefs 32:43-48.

Pompanon F, Deagle BE, Symondson WOC, Brown DS, Jarman SN, Taberlet P. 2012. Who is eating what: diet assessment using next generation sequencing. Molecular Ecology 21:1931-1950.

Pratchett MS. 2005. Dietary overlap among coral-feeding butterflyfishes (Chaetodontidae) at Lizard Island, northern Great Barrier Reef. Marine Biology 148:373-382.

Pratchett MS. 2007. Dietary selection by coral-feeding butterflyfishes (Chaetodontidae) on the Great Barrier Reef, Australia. Raffles Bulletin of Zoology:171-176.

Pratchett MS, Berumen ML. 2008. Interspecific variation in distributions and diets of coral reef butterflyfishes (Teleostei: Chaetodontidae). Journal of Fish Biology 73:1730-1747.

Randall JE. 1967. Food habits of reef fishes of the West Indies. Studies in Tropical Oceanography 5:665-847.

Ranwez V, Harispe S, Delsuc F, Douzery EJP. 2011. MACSE: Multiple Alignment of Coding SEquences accounting for frameshifts and stop codons. PloS One 6:e22594.

Rawlinson KA, Gillis JA, Billings RE, Borneman EH. 2011. Taxonomy and life history of the Acropora-eating flatworm Amakusaplana acroporae nov. sp. (Polycladida: Prosthiostomidae). Coral Reefs 30:693-705.

Robertson DR, Lassig B. 1980. Spatial distribution patterns and coexistence of a group of territorial damselfishes from the Great Barrier reef. Bulletin of Marine Science 30:187-203.

Ross ST. 1986. Resource partitioning in fish assemblages - a review of field studies. Copeia 2:352-388.

Rotjan R, Lewis S. 2008. Impact of coral predators on tropical reefs. Marine Ecology Progress Series 367:73-91.

Rouzé H, Lecellier G, Mills SC, Planes S, Berteaux-Lecellier V, Stewart H. 2014. Juvenile Trapezia spp. crabs can increase juvenile host coral survival by protection from predation. Marine Ecology Progress Series 515:151-159.

Rouzé H, Lecellier G, Langlade MJ, Planes S, Berteaux-Lecellier V. 2015. Fringing reefs exposed to different levels of eutrophication and sedimentation can support similar benthic communities. Marine Pollution Bulletin 92:212-221.

Shehzad W, McCarthy TM, Pompanon F, Purevjav L, Coissac E, Riaz T, Taberlet P. 2012. Prey preference of snow leopard (Panthera uncia) in South Gobi, Mongolia. PloS One 7:e32104. 
537

538

539

540

541

542

543

544

545

546

547

548

549

550

551

552

553

554

555

556

557

558

559

560

561

562

563

564

565

566 567

568

569

Sheppard SK, Bell J, Sunderland KD, Fenlon J, Skervin D, Symondson WOC. 2005. Detection of secondary predation by PCR analyses of the gut contents of invertebrate generalist predators. Molecular Ecology 14:4461-4468.

Shima JS, Osenberg CW, Stier AC. 2010. The vermetid gastropod Dendropoma maximum reduces coral growth and survival. Biology Letters 6:815-818.

Simon-Blecher N, Achituv Y. 1997. Relationship between the coral pit crab Cryptochirus coralliodytes Heller and its host coral. Journal of Experimental Marine Biology and Ecology 215:93-102.

Stella JS, Pratchett MS, Hutchings PA, Jones GP. 2011. Coral-associated invertebrates: diversity, ecological importance and vulnerability to disturbance. In: Oceanography and Marine Biology: an Annual Review, Vol 49. 43-104.

Stella JS, Jones GP, Pratchett MS. 2010. Variation in the structure of epifaunal invertebrate assemblages among coral hosts. Coral Reefs 29:957-973.

Stewart HL, Holbrook SJ, Schmitt RJ, Brooks AJ. 2006. Symbiotic crabs maintain coral health by clearing sediments. Coral Reefs 25:609-615.

Stier AC, McKeon CS, Osenberg CW, Shima JS. 2010. Guard crabs alleviate deleterious effects of vermetid snails on a branching coral. Coral Reefs 29:1019-1022.

Stier AC, Gil MA, McKeon CS, Lemer S, Leray M, Mills SC, Osenberg CW. 2012. Housekeeping mutualisms: do more symbionts facilitate host performance? PloS One 7:e32079.

Stier AC, Leray M. 2014. Predators alter community organization of coral reef cryptofauna and reduce abundance of coral mutualists. Coral Reefs 33:181-191.

Sussman M, Loya Y, Fine M, Rosenberg E. 2003. The marine fireworm Hermodice carunculata is a winter reservoir and spring-summer vector for the coral-bleaching pathogen Vibrio shiloi. Environmental Microbiology 5:250-255.

Symondson WOC. 2002. Molecular identification of prey in predator diets. Molecular Ecology $11: 627-641$.

Taberlet P, Coissac E, Pompanon F, Brochmann C, Willerslev E. 2012. Towards next-generation biodiversity assessment using DNA metabarcoding. Molecular Ecology 21:2045-2050.

Talbot FH, Russell BC, Anderson GR V. 1978. Coral reef fish communities - unstable, high diversity systems. Ecological Monographs 48:425-440.

Turner S. 1994. The biology and population outbreaks of the corallivorous gastropod Drupella on Indo-Pacific reefs. Oceanography and Marine Biology 32:461-530. 
570 Vestheim H, Jarman SN. 2008. Blocking primers to enhance PCR amplification of rare 571 sequences in mixed samples - a case study on prey DNA in Antarctic krill stomachs.

$572 \quad$ Frontiers in Zoology 5:12.

573 Waldner RE, Robertson DR. 1980. Patterns of habitat partitioning by eight species of territorial 574 Carribbean damselfishes (Pisces: Pomacentridae). Bulletin of Marine Science 30:171-186.

575 Williams D, Miller M. 2005. Coral disease outbreak: pattern, prevalence and transmission in 576 Acropora cervicornis. Marine Ecology Progress Series 301:119-128.

577 Wright SJ. 2005. Tropical forests in a changing environment. Trends in Ecology \& Evolution $578 \quad 20: 553-560$.

579 


\section{Table 1 (on next page)}

List of primers used in this study 


\begin{tabular}{lll}
\hline Primer label & Sequence (5' '-3') & Reference \\
\hline mlCOIintF & GGWACWGGWTGAACWGTWTAYCCYCC & Leray et al. 2013a \\
jgHCO2198 & TAIACYTCIGGRTGICCRAARAAYCA & Geller et al. 2013 \\
Narmatus_Blocking & CAAAGAATCAAAACAGGTGTTGATAAAGA-C3 & Leray et al. 2013b \\
Parcatus_Blocking & CAAAGAATCAGAACAGATGTTGGTAAAGA-C3 & Leray et al. 2013b \\
Cmaculatus_Blocking & CAAAGAATCAGAATAGGTGTTGGTACAGA-C3 & Herein \\
\hline
\end{tabular}


Figure 1 (on next page)

Map of the study location 


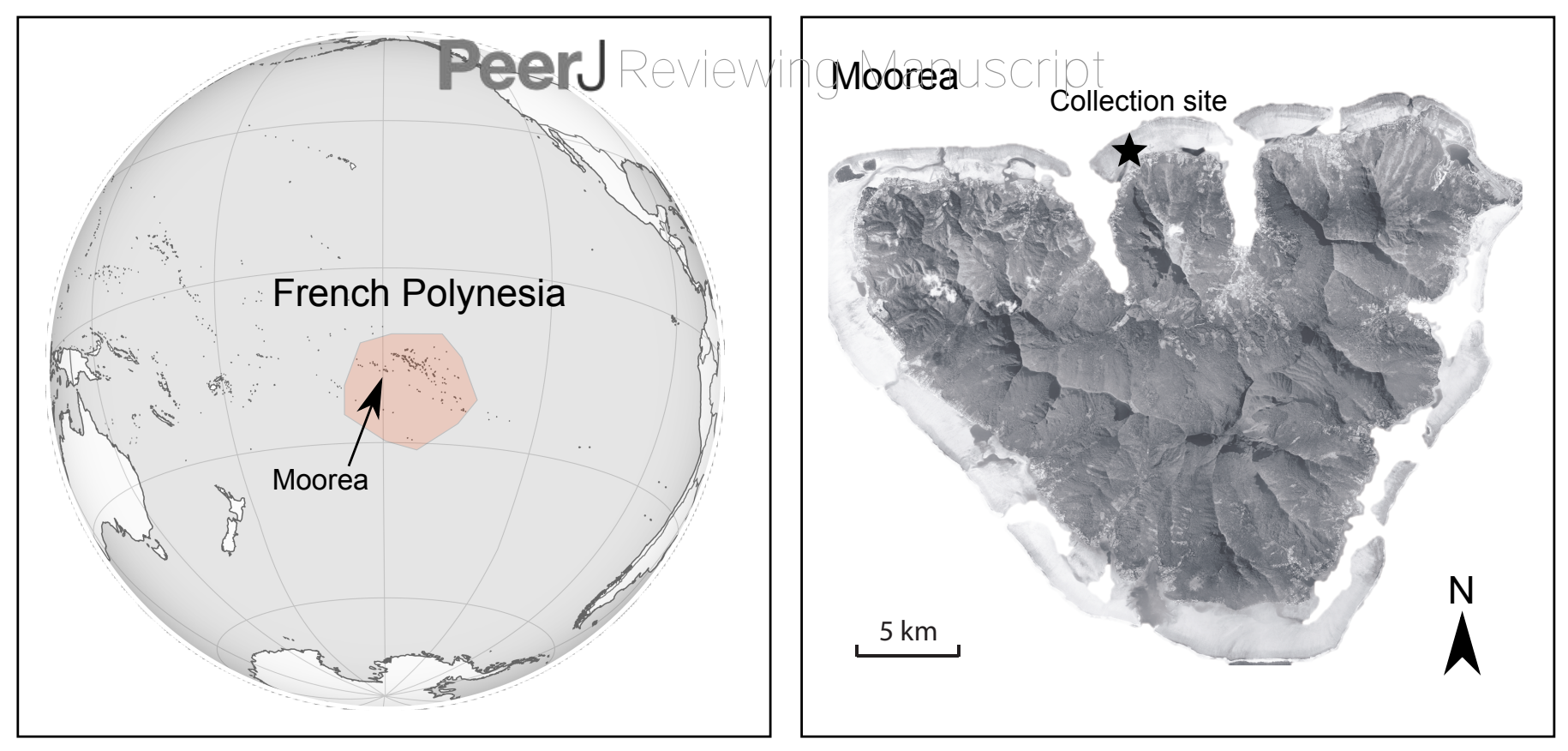


Figure 2 (on next page)

Rarefaction curves to evaluate the completeness of the sequencing effort at describing the diversity of dietary items in the gut contents of three coral reef fish species 


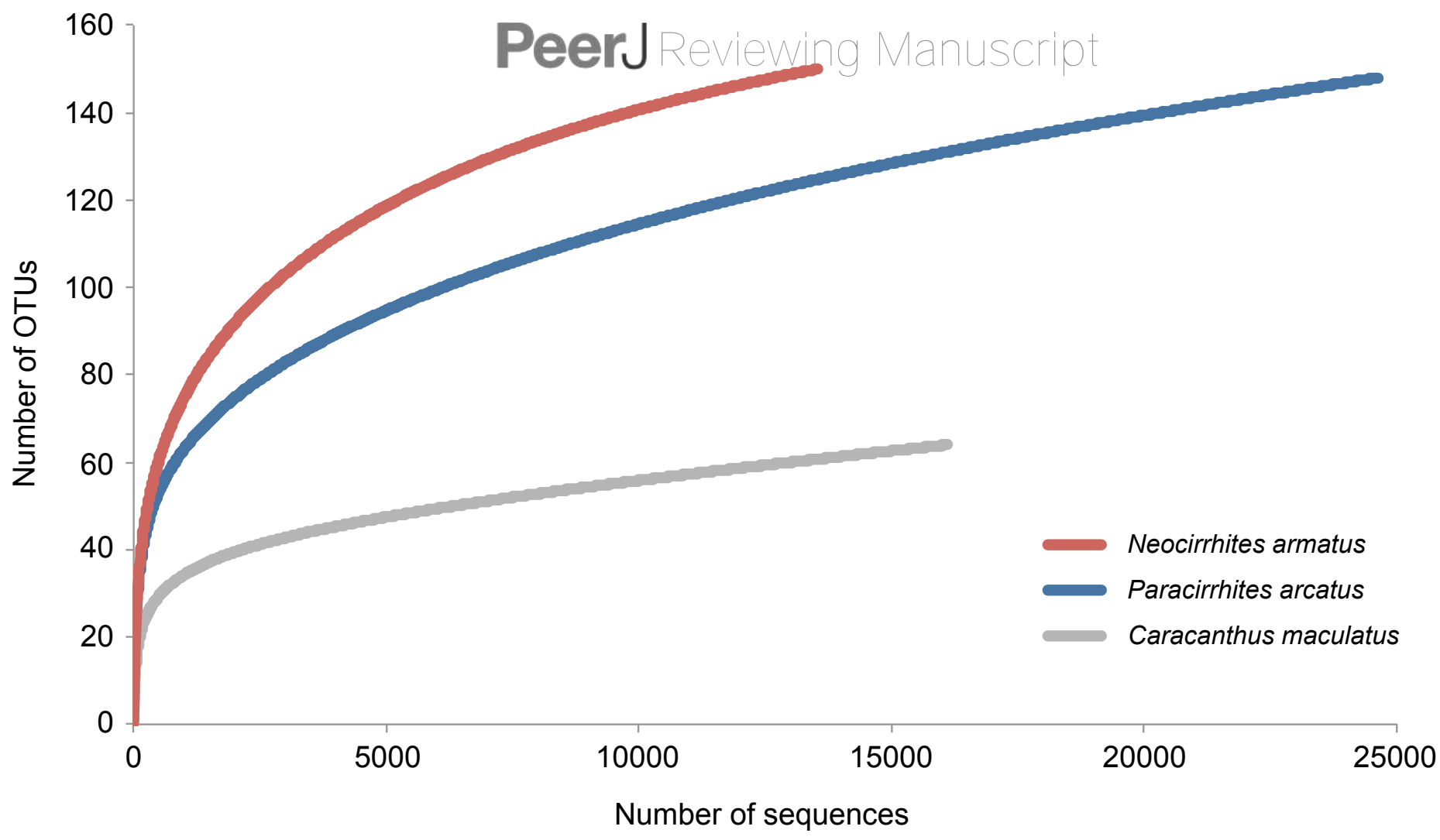


Figure 3 (on next page)

Proportion of identified OTUs in relation to the number of sequences they represent

Whenever OTU sequence similarity to a reference barcode was $<98 \%$, we used the Phylogenetic Bayesian assignment tool implemented in SAP to assign OTUs to a higher taxonomic group 


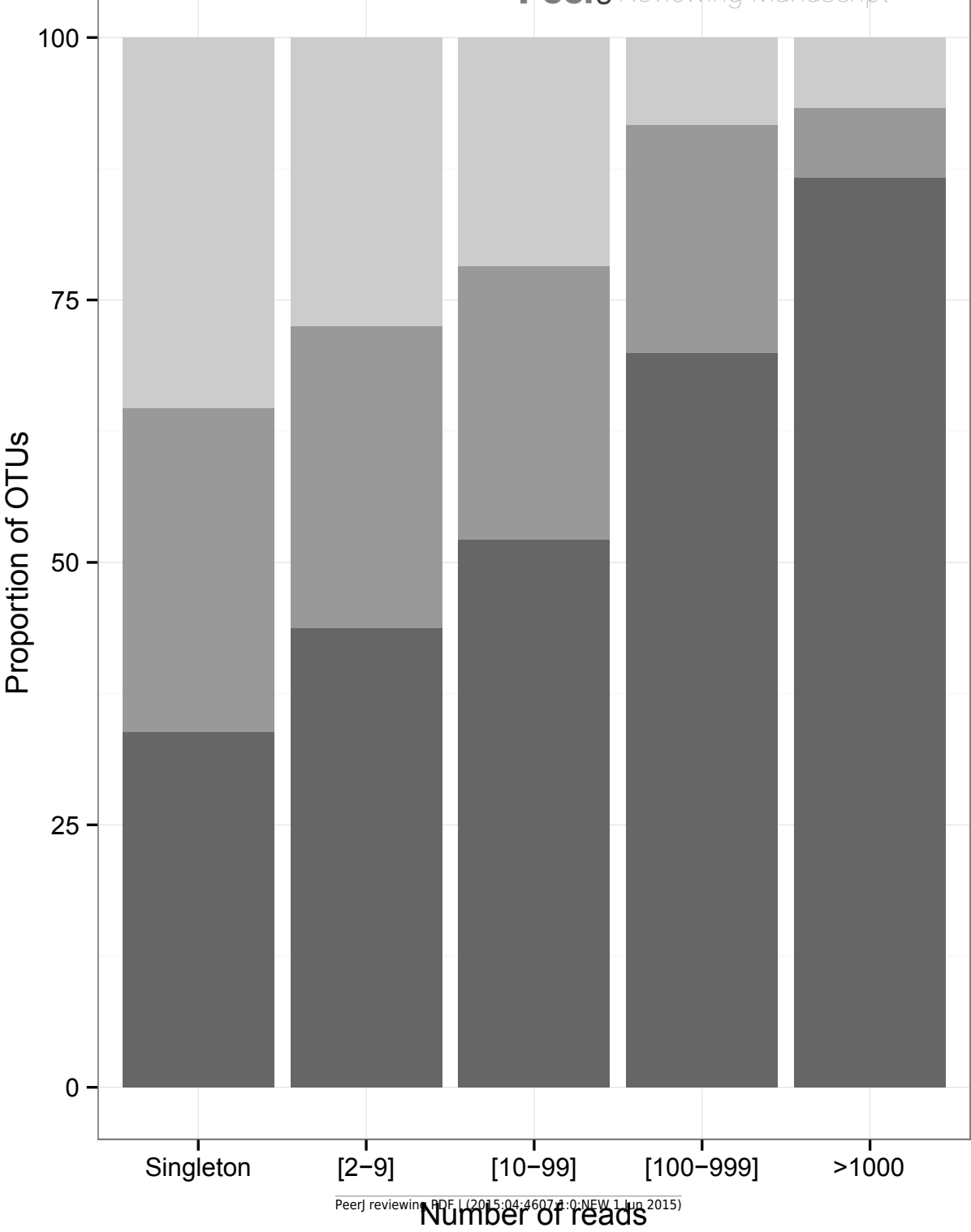

$>98 \%$ similarity to ref. barcode Phylogenetic assignment (SAP) Unidentified 
Figure 4 (on next page)

Dietary partitioning among the three predatory fish species

Left neighbor-joining phylogeny using LogDet distance model based on a constraint topology of major clades represents relationship among the 66 prey OTUs that comprise $>1 \%$ of any one species diet. Thickness of linkages to right represents relative proportion of predatory diets. Six shared species are highlighted with circles. Fish images courtesy of D. Liittschwager. The 66 OTUs are highlighted in Appendix I 
$\Gamma$ demosponge PeerJReviewing Manuscript

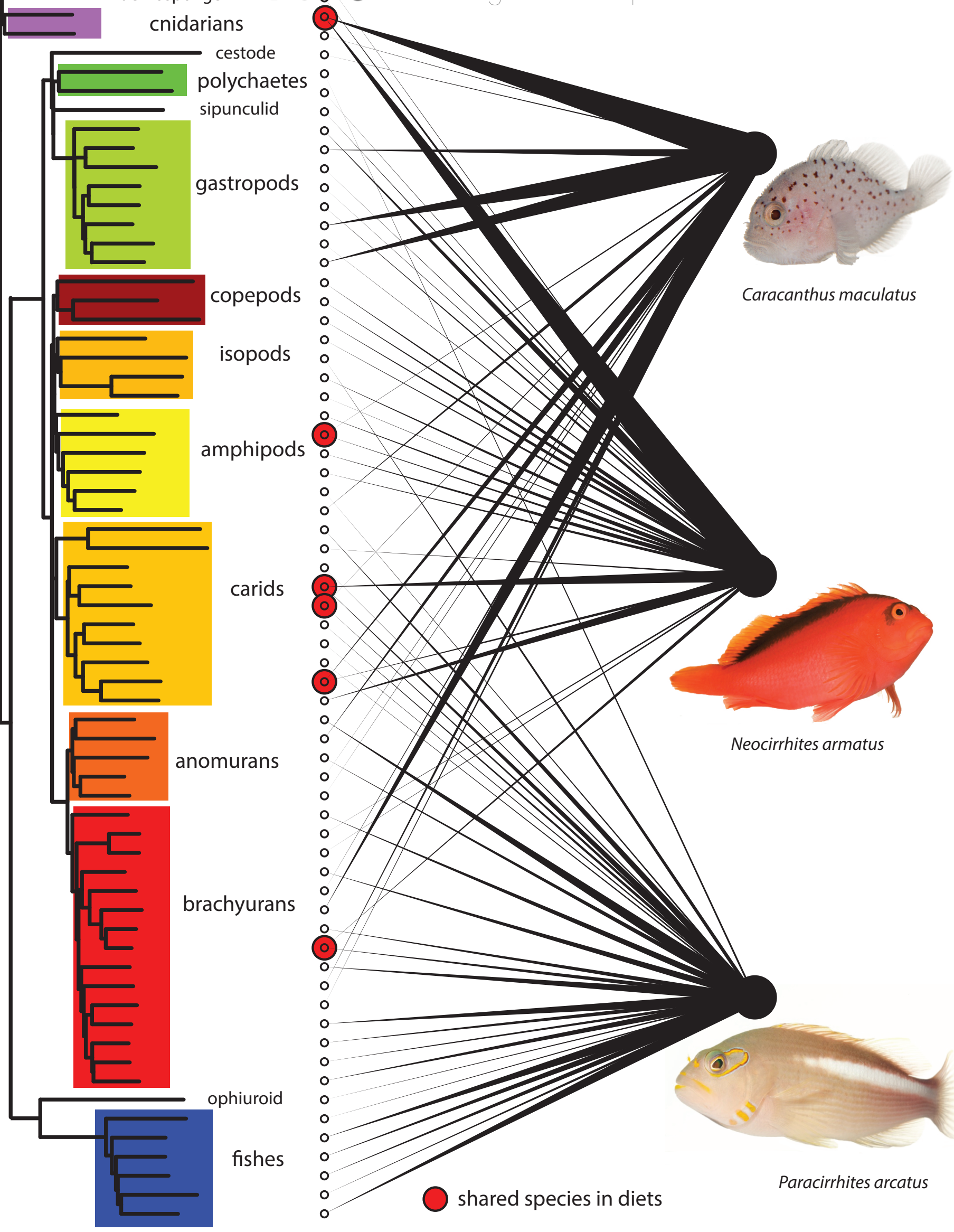

Peer) reviewing PDF | (2015:04:4607:1:0:NEW I Jun 2015) thickness corresponds to \% of total diet (only prey $>1 \%$ of diet represented) 